\title{
Evaluation of the reactivity of titanium with mould materials during casting
}

\author{
R L SAHA, T K NANDY, R D K MISRA and K T JACOB* \\ Defence Metallurgical Research Laboratory, PO Kanchanbagh, Hyderabad 500 258, India \\ *Department of Metallurgy, Indian Institute of Science, Bangalore 560012 , India \\ MS received 11 August 1989; revised 25 September 1989
}

\begin{abstract}
A methodology for evaluating the reactivity of titanium with mould materials during casting has been developed. Microhardness profiles and analysis of oxygen contamination have provided an index for evaluation of the reactivity of titanium. Microhardness profile delineates two distinct regions, one of which is characterised by a low value of hardness which is invariant with distance. The reaction products are uniformly distributed in the metal in this region. The second is characterised by a sharp decrease in microhardness with distance from the metal-mould interface. It represents a diffusion zone for solutes that dissolve into titanium from the mould. The qualitative profiles for contaminants determined by scanning electron probe microanalyser and secondary ion mass spectroscopy in the as-cast titanium were found to be similar to that of microhardness, implying that microhardness can be considered as an index of the contamination resulting from metal-mould reaction.
\end{abstract}

Keywords. Titanium; reactivity; casting; oxygen; microhardness; secondary electron probe microanalysis; secondary ion mass spectrometry.

\section{Introduction}

Although titanium is one of the most recent engineering metals, it has found a number of applications in the aerospace, marine and general engineering industries. The high specific strengths, high fatigue and creep strengths and excellent corrosion resistances of titanium and its alloys have facilitated their acceptance as engineering materials.

One of the oldest and most economical methods for producing components from liquid metal is by casting (Tylecote 1979). This method ensures high material utilisation and cost effectiveness due to improved design flexibility and reduced machining requirements. Applications of titanium casting include non-rotating engine structures and airframe parts. Cast components up to $700 \mathrm{~kg}$ have been produced in rammed graphite moulds for chemical industries. Investment castings weighing from just a few grams up to about $200 \mathrm{~kg}$ have been produced for critical aerospace and biomedical applications (Newman 1980; Froes 1987; Thorne and Barice 1988). The use of titanium castings is limited by its reactivity with mould materials and its affinity for atmospheric gases. The reaction of titanium with the constituents of mould is expected to result in metal penetration into the mould, adherence of fused sand, surface contamination of the casting, scales and other types of surface defects. A number of parameters influence the reaction of the liquid metal with the mould. Metal composition, mould additions, static and kinetic energies of the liquid metal and many other variables are known to have a strong influence on the extent of reaction. Knowledge of the causes and prevention of reaction is primarily phenomenological. Mechanisms such as liquid metal penetration, chemical reaction, vapour state penetration, water explosion and 
thermal expansion of mould aggregates have found acceptance in explaining in general the reactivity of the metal with the mould.

It has been difficult to quantify the chemical reactivity of titanium metal with the constituents of oxide moulds until recently. An attempt is made here to study the reactivity by determination of microhardness profile and oxygen contamination in the as-cast titanium. Oxygen has a high solubility $(\sim 3.5 \mathrm{wt} \%$ at $673 \mathrm{~K}$ temperature; Murray and Wriedt 1986) in titanium and has a significant hardening effect. Both zircon sand moulds and investment moulds were used in this study. The investment casting process is used in situations where contamination-free surfaces and high dimensional accuracies are required in high quality intricate shapes.

\section{Experimental}

First the relationship between oxygen concentration and microhardness was established by melting titanium buttons ( $\sim 40 \mathrm{~mm}$ dia) containing up to $\sim 20,000 \mathrm{ppm}$ oxygen in a non-consumable vacuum arc furnace. Samples were polished and microhardness measurements (Vicker's hardness) were made using a $50 \mathrm{~g}$ load. Average grain size was $400 \mu \mathrm{m}$.

Reactivity of titanium with the mould mix was studied under different mould conditions by casting $20 \mathrm{~mm}$ dia rods in zircon sand moulds using a drop cast hearth in a non-consumable vacuum arc furnace (Mukherji et al 1985). Zircon moulds were prepared by mulling the zircon sand, $3 \%$ sodium silicate, $2.5 \%$ temper water and $7.5 \%$ of $\mathrm{ZrO}_{2}$, followed by ramming the mould-mix mass on a wooden pattern. The mould was subsequently hardened by passing $\mathrm{CO}_{2}$ gas over the surface of the mould for $30-60 \mathrm{~s}$. The mould was fired at $1473 \mathrm{~K}$ for $2 \mathrm{~h}$ before introducing it in the vacuum arc furnace for casting. The resulting cast rods were cut for microstructural studies, microhardness evaluation and bulk oxygen analysis. X-ray diffraction studies were carried out on the mould mix to determine any changes in the chemical form of mould mix constituents.

The wax pattern for investment casting of titanium was made by injecting wax into a simple cylindrical metal mould $(20 \mathrm{~mm}$ dia $\times 100 \mathrm{~mm})$ with integral pouring basin. Wax patterns were then inspected and dressed to eliminate any imperfections resulting from injection. The pattern was dip-coated with a primary slurry coat containing very fine particles of $\mathrm{Y}_{2} \mathrm{O}_{3}$ and colloidal silica. It was then stuccoed after draining the excess slurry and given another coat with the same slurry. Later, stuccoing was done with coarser zircon sand and the shell thickness of $5 \mathrm{~mm}$ was built up with alternative dipping and stuccoing. The shells were dried at a temperature of $295 \mathrm{~K}$ for $24 \mathrm{~h}$. This was followed by dewaxing in an autoclave maintained at $440 \mathrm{~K}$ and a pressure of about $0.5 \mathrm{MPa}(80 \mathrm{psi})$, followed by firing at $1123 \mathrm{~K}$.

\section{Results and discussion}

\subsection{Reactivity of titanium during casting in zircon moulds}

As a result of metal-mould reaction, hydrogen, oxygen, silicon and zirconium from the constituents of the mould mix $\left(\mathrm{ZrSiO}_{4}, \mathrm{ZrO}_{2}, \mathrm{SiO}_{2}\right.$ and $\left.\mathrm{H}_{2} \mathrm{O}\right)$, contaminate the 
metal. The extent of contamination is related not only to the thermodynamic stability of the refractory oxides but is also dependent on the rate of dissolution.

The relationship between oxygen content and microhardness of titanium buttons $(\sim 40 \mathrm{~mm} \mathrm{dia})$ containing up to $20,000 \mathrm{ppm}$ oxygen is presented in figure 1 . The microhardness is directly related to oxygen content. From this correlation, microhardness values corresponding to oxygen content in as-cast titanium can be estimated. The relationship between microhardness and oxygen content is expected to vary marginally with the type of casting since microhardness also depends on microstructure.

3.1a Surface contamination of titanium: Analysis of contaminants $(\mathrm{O}, \mathrm{H}, \mathrm{Zr}$ and $\mathrm{Si})$ at the centre and surface of the titanium rods cast in moulds fired at $1473 \mathrm{~K}$ is given in table 1. For comparison the analysis of titanium buttons used as charge for casting is also included. The analysis of the contaminants at the surface of the casting may not have a high degree of accuracy because the samples for chemical analysis were obtained by turning the cast rod to a depth of $\sim 2 \mathrm{~mm}$. However, appreciable increase in microhardness near the surface of titanium casting is indicative of severe contamination (figure 2). It may be seen that hardness at the surface is of the order of $530 \mathrm{VHN}$. The equivalent oxygen concentration from figure 1 is $13,800 \mathrm{ppm}$. However, this estimate is not very accurate because other contaminants ( $\mathrm{Si}$ and $\mathrm{Zr}$ ) may also contribute to hardening. The reproducibility of measurements at the surface of the casting was not very satisfactory because of difficulties in collection of samples from the surface.

The reaction of the molten titanium with the moulds results in the contamination of the titanium casting with the constituents of the mould. As a primary step in evaluating the reactivity of titanium with the mould mix, microhardness profiles were generated in the radial direction, starting from the surface of the titanium rod. The microhardness profile was found to delineate two distinct regions (figure 2), one of which, at a distance $>700 \mu \mathrm{m}$, is characterised by a low and constant value of

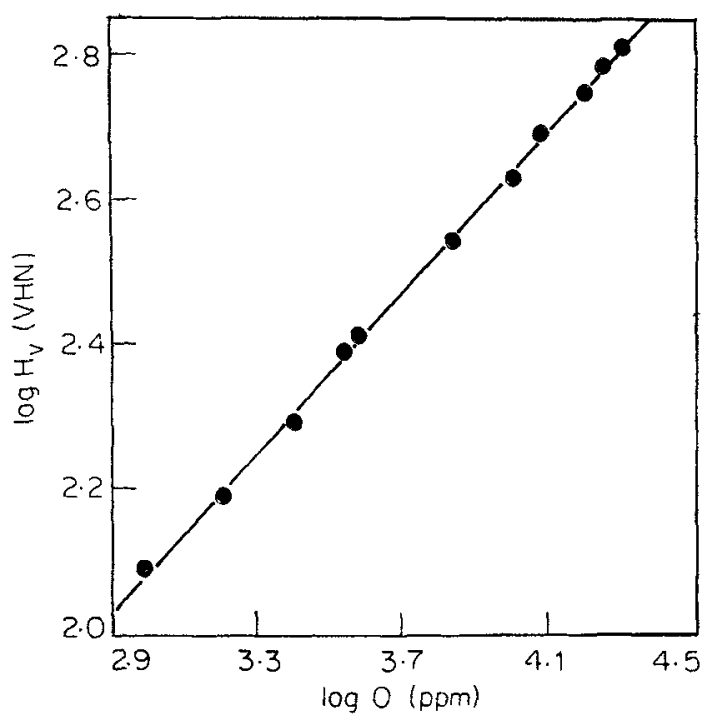

Figure 1. Effect of oxygen content on microhardness of cast titanium buttons. 
Table 1. Analysis of contaminants $(\mathrm{O}, \mathrm{H}, \mathrm{Zr}$ and $\mathrm{Si})$ at the surface and centre of the titanium rod cast in sodium silicate bonded zircon mould containing $7.5 \% \mathrm{ZrO}_{2}$ and fired at $1473 \mathrm{~K}$.

\begin{tabular}{|c|c|c|c|c|c|c|}
\hline & \multirow{2}{*}{$\begin{array}{l}\text { Titanium } \\
\text { buttons } \\
\text { used for } \\
\text { casting } \\
\text { (1) }\end{array}$} & \multicolumn{2}{|c|}{$\begin{array}{l}\text { Cast titanium rod } \\
\text { location }\end{array}$} & \multirow{2}{*}{\multicolumn{2}{|c|}{ Contaminants }} & \multirow[b]{3}{*}{$\begin{array}{l}\text { Due to } \\
\text { mould } \\
\text { oxide }\end{array}$} \\
\hline & & $\begin{array}{l}\text { Surface } \\
\text { (2) }\end{array}$ & $\begin{array}{c}\text { Bulk } \\
(3)\end{array}$ & & & \\
\hline $\begin{array}{l}\text { Hardness (VHN) } \\
\text { Equivalent oxygen (ppm) } \\
\quad \text { (from figure 1) }\end{array}$ & $\begin{array}{r}120 \\
1000\end{array}$ & $\begin{array}{r}530 \\
13800\end{array}$ & $\begin{array}{r}160 \\
1585\end{array}$ & $\begin{array}{c}\text { Total } \\
\text { increase } \\
(3-1)\end{array}$ & $\begin{array}{l}\text { Due to } \\
\text { moisture in } \\
\text { the mould }\end{array}$ & \\
\hline Hydrogen (ppm) & 40 & * & 48 & 8 & 8 & - \\
\hline Oxygen (ppm) & 800 & * & 1160 & 360 & $64 * *$ & 296 \\
\hline $\mathrm{Zr}(\mathrm{wt} \%)$ & $<0.01$ & $0 \cdot 35$ & $<0.01$ & - & - & - \\
\hline $\mathrm{Si}(\mathrm{wt} \%)$ & $<0.01$ & 0.30 & $<0.01$ & - & - & - \\
\hline
\end{tabular}

* Suitable sample for gas analysis was not available.

**From stoichiometry: $\mathrm{H}_{2} \mathrm{O} \rightarrow 2[\mathrm{H}]_{\mathrm{Ti}}+[\mathrm{O}]_{\mathrm{Ti}}$.

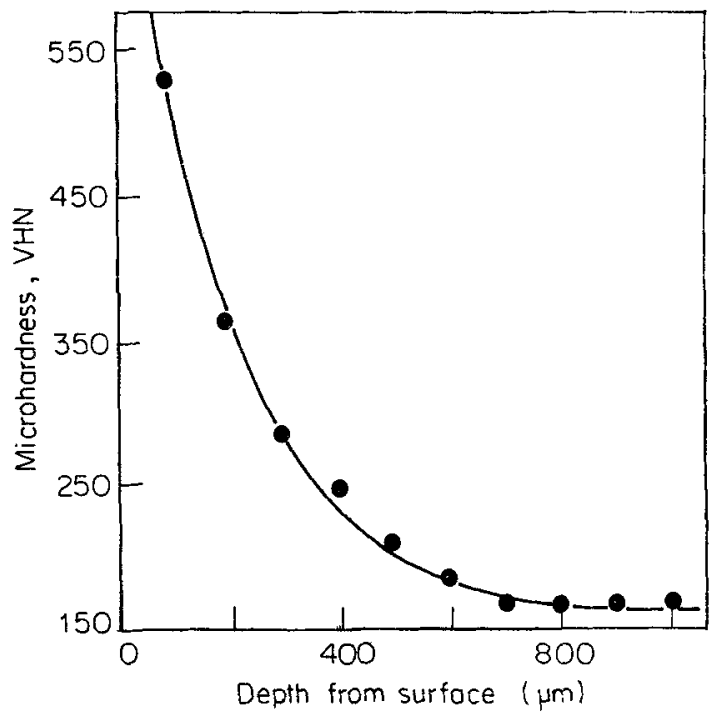

Figure 2. Microhardness as a function of distance from surface for titanium cast in sodium silicate bonded zircon mould containing $7 \cdot 5 \% \mathrm{ZrO}_{2}$ and fired at $1473 \mathrm{~K}$.

hardness. In the second region, microhardness decreases with increase in depth from the mould interface. It can be inferred from these observations that distribution of contaminants arising due to the reaction of titanium with the mould mix occurs in two steps. The invariant nature of the microhardness in the bulk is indicative of uniform composition. The products of reaction of titanium with the mould mix are uniformly distributed in the bulk of the titanium casting.

As the liquid metal fills the mould, it reacts with the mould and preferentially dissolves the constituents of the mould $(\mathrm{O}, \mathrm{Si}$ and $\mathrm{Zr})$. The presence of turbulence in the metal and high diffusion rates of solutes in the liquid state ensure uniform distribution of contaminants in the liquid metal. The reaction of titanium with the 
mould mix, however, continues at the mould interface, even after the decay of turbulence in the liquid and commencement of solidification at the interface. This results in impurity gradients between the surface and the bulk. Whenever a gradient exists, diffusional processes become operative to minimise the gradient. In the casting, diffusion occurs under both concentration and temperature gradients. The region of microhardness profile characterised by decrease in hardness with distance from the metal-mould interface can be designated as a diffusion zone. The diffusion zone or the distance at which the microhardness profile becomes invariant extends to $\sim 700 \mu \mathrm{m}$ from the interface in the cast titanium rods of $20 \mathrm{~mm}$ dia. This diffusion distance of $700 \mu \mathrm{m}$ remains unaltered despite changes in the mould conditions such as increases in $\mathrm{ZrO}_{2}$ concentration and mould firing temperatures (Saha et al 1989).

3.1b Bulk contamination of titanium: This region starts at the point where the microhardness profile becomes invariant (figure 2). Since the contaminants distribute themselves uniformly in this region, the analysis of this region may provide a more reliable index for evaluation of the stability of the mould against titanium. Table 1 shows that contamination due to $\mathrm{Si}$ and $\mathrm{Zr}$ is insignificant. The marginal increase in hydrogen is not expected to contribute significantly to hardness. Thus the higher bulk hardness can be attributed to increase in oxygen contamination. Thus, the invariant part of the microhardness profile represents the oxygen content of the bulk. The extent of relative displacement of the invariant part of the profile is a measure of the extent of the metal-mould reaction.

The increase in hydrogen content can be ascribed to the presence of moisture in the mould. Moisture dissolves in liquid titanium as oxygen and hydrogen atoms,

$$
\mathrm{H}_{2} \mathrm{O} \rightarrow 2[\mathrm{H}]_{\mathrm{Ti}}+[\mathrm{O}]_{\mathrm{Ti}} \text {. }
$$

The amount of oxygen picked up by the metal from moisture in the mould can be estimated from the hydrogen analyses and stoichiometry of the reaction. It may be seen from table 1 that the total increase in oxygen contamination is higher than the amount that can be attributed to moisture. The difference in oxygen pick up is therefore a consequence of the reaction of the liquid metal with various refractory oxides present in the mould. It is further observed from table 1 that oxygen contamination due to refractory oxides is significantly higher than the stoichiometric value one may derive corresponding to metallic ( $\mathrm{Si}$ and $\mathrm{Zr}$ ) contamination in the bulk. If the mould oxides dissovled completely in liquid titanium then there should have been a mass balance between oxygen and metallic constituents. This observation therefore suggests that mould oxides are not fully dissolved. Oxygen from the mould oxides is preferentially leached into liquid titanium leaving behind the metallic components in the mould as suboxides or intermetallics of titanium.

3.1c Correlation of microhardness profiles with diffusional processes: The decrease in hardness with distance from the surface (figure 2) can be attributed to the decrease in the extent of contamination. The invariant part of the profile is characterised by a uniform distribution of contaminants. It may be noted from table 1 that contamination of $\mathrm{Zr}$ and $\mathrm{Si}$ at the surface is higher than that in the bulk. It is therefore interesting to map the variation of each element $(\mathrm{O}, \mathrm{Zr}$ and $\mathrm{Si})$ with distance from the surface of the casting.

The X-ray elemental maps taken from a representative area (figure $3 a$ ) shows 
enrichment of Si (figure 3b) and $\mathrm{Zr}$ (figure 3c) at the casting surface. After a certain distance from the surface the distribution of these elements tends to become negligible. The secondary electron micrograph displays coarse grain boundaries in the contaminated zone (figure 3a). X-ray maps taken at higher magnifications (figure 4) shows that $\mathrm{Si}$ is significantly enriched in the grain boundary phase. On the basis of the X-ray analysis of interface sand (table 2) which indicates the presence of $\mathrm{Ti}_{5} \mathrm{Si}_{3}$, it can be speculated that the Si-enriched phase at the grain boundary is $\mathrm{Ti}_{5} \mathrm{Si}_{3}$.

To obtain $\mathrm{Zr}$ and Si profile near the titanium-zircon mould interface, the X-ray intensity counts are plotted as a function of distance from the surface in figure 5 . The profiles indicate considerable enrichment of $\mathrm{Si}$ and $\mathrm{Zr}$ at the surface which decreases with increase in depth. The $\mathrm{Si}$ and $\mathrm{Zr}$ counts attain a constant value at a distance of $110 \mu \mathrm{m}$ and $90 \mu \mathrm{m}$ respectively from the surface. These distances can be considered their respective diffusion depths. As expected, the X-ray intensity count for titanium increases with depth. The increase in titanium concentration with increase in distance from the surface is a consequence of decrease in $\mathrm{Zr}, \mathrm{Si}$ and $\mathrm{O}$ contamination with distance from the casting surface. The general nature of $\mathrm{Si}$ and $\mathrm{Zr}$ profiles resembles that of the microhardness profile (figure 2). However, the diffusion depth of about $100 \mu \mathrm{m}$ obtained for $\mathrm{Si}$ and $\mathrm{Zr}$ is appreciably lower than that of about $700 \mu \mathrm{m}$ displayed by the microhardness profile. Since only three diffusing solutes $(\mathrm{O}, \mathrm{Si}$ and $\mathrm{Zr})$ were identified and diffusion depths for $\mathrm{Si}$ and $\mathrm{Zr}$ are less than $100 \mu \mathrm{m}$, the extended diffusion zone of $700 \mu \mathrm{m}$ displayed by microhardness profiles can be attributed to oxygen. The higher diffusion depth for oxygen is consistent with its lower atomic radii and hence higher rate of diffusion.

Approximate diffusion depth of an impurity solute $(x)$ in a metal is given by [Raghavan 1985]

$$
x=(D t)^{\frac{1}{2}}
$$

where $D$ is the diffusion coefficient $\left(\mathrm{m}^{2} \mathrm{~s}^{-1}\right)$ and $t$ is the time of diffusion (s). The diffusion coefficient at any temperature can be calculated from the relationship,

$$
D=D_{0} \exp (-Q / R T)
$$

where $D_{0}$ is the pre-exponential factor $\left(\mathrm{m}^{2} \mathrm{~s}^{-1}\right), Q$ is the activation energy $\left(\mathrm{J} \mathrm{mol}^{-1}\right)$,

Table 2. Diffusion data on $\mathrm{O}, \mathrm{Si}, \mathrm{Zr}$ and $\mathrm{Al}$ in titanium $D=D_{0} \exp (-Q / R T), R=8 \cdot 31 \mathrm{~J}$ $\mathrm{mol}^{-1} \mathrm{~K}^{-1}$.

\begin{tabular}{lccccccc}
\hline & \multicolumn{3}{c}{$\alpha$-Ti (below 1156 K) } & \multicolumn{4}{c}{$\beta$-Ti (above 1156 K) } \\
\cline { 2 - 7 } $\begin{array}{l}\text { Diffusion } \\
\text { solutes } \\
\text { in } \mathrm{Ti}\end{array}$ & $\begin{array}{c}D_{0} \\
\left(\mathrm{~m}^{2} \mathrm{~s}^{-1}\right)\end{array}$ & $\begin{array}{c}\mathrm{Q} \\
\left(\mathrm{kJ} \mathrm{mol}^{-1}\right)\end{array}$ & Reference & $\begin{array}{c}D_{0} \\
\left(\mathrm{~m}^{2} \mathrm{~s}^{-1}\right)\end{array}$ & $\begin{array}{c}\mathrm{Q} \\
\left(\mathrm{kJ} \mathrm{mol}^{-1}\right)\end{array}$ & $\begin{array}{c}\text { Tempera- } \\
\text { ture range } \\
(\mathrm{K})\end{array}$ & Reference \\
\hline $\mathrm{O}$ & $1 \times 10^{-4}$ & 188 & $\begin{array}{l}\text { (David } \text { et al } \text { al } \\
1.4 \times 10^{-5}\end{array}$ & 138 & $1155-1425$ & $\begin{array}{l}\text { (Ignatov } \\
\text { et al 1973) }\end{array}$ \\
$\mathrm{Si}$ & $1.6 \times 10^{-1}$ & 184.5 & $\begin{array}{l}\text { (Mahoney } \\
\text { and Paton } \\
1977)\end{array}$ & - & - & - & - \\
$\mathrm{Zr}$ & - & - & - & $4.7 \times 10^{-7}$ & 148 & $1193-1773$ & $\begin{array}{l}\text { (Pavlinov } \\
\text { 1967) }\end{array}$ \\
\hline
\end{tabular}



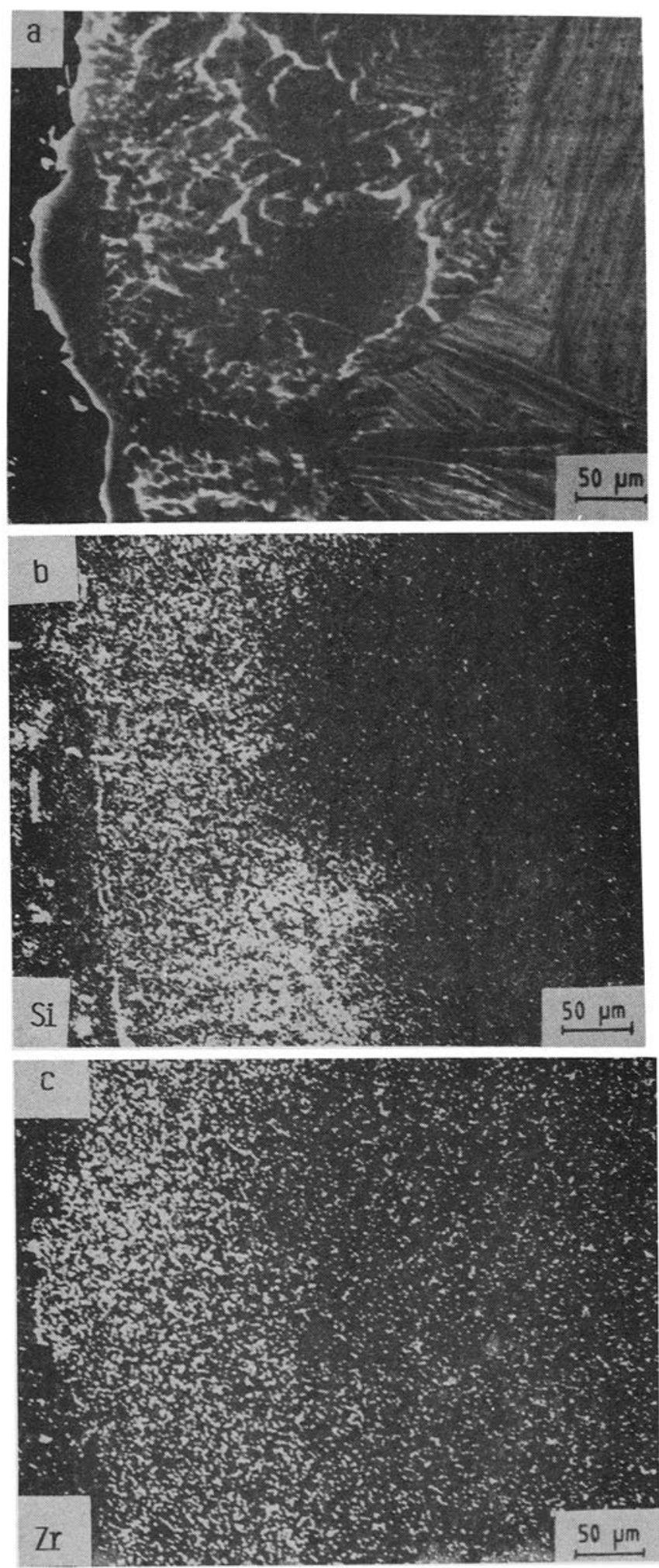

Figure 3. For caption, see p. 488. 

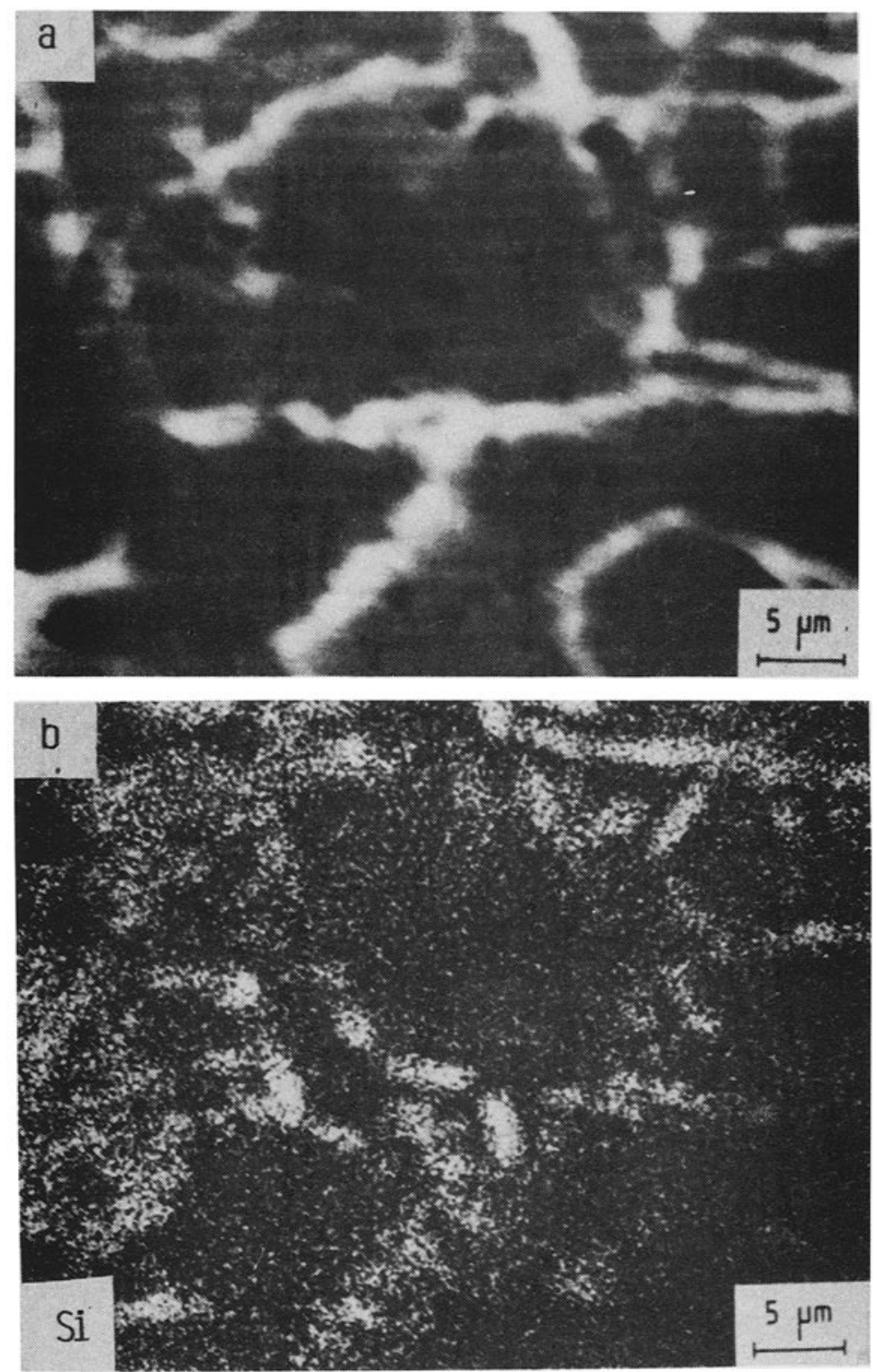

Figure 4. Magnified view of figure 3 showing significant enhancement of $\mathrm{Si}$ at the grain boundaries close to the titanium-zircon mould interface, (a) secondary electron image and (b) X-ray map of $\mathrm{Si}$.

$R$ is the gas constant $\left(8.31 \mathrm{~J} \mathrm{~mol}^{-1} \mathrm{~K}^{-1}\right)$ and $T$ is the absolute temperature $(\mathrm{K})$. The data for the diffusion of $\mathrm{O}, \mathrm{Si}$ and $\mathrm{Zr}$ in titanium are listed in table 3. Diffusion data below the melting point of titanium $(1943 \mathrm{~K})$ would be more appropriate for

Figure 3. Secondary electron micrograph (a) and X-ray elemental maps of $\mathrm{Si} \mathrm{(b)}$ and $\mathrm{Zr}$ (c) displaying enhancement of $\mathrm{Si}$ and $\mathrm{Zr}$ near the interface of titanium casting in sodium silicate bonded zircon mould containing $7.5 \% \mathrm{ZrO}_{2}$. 


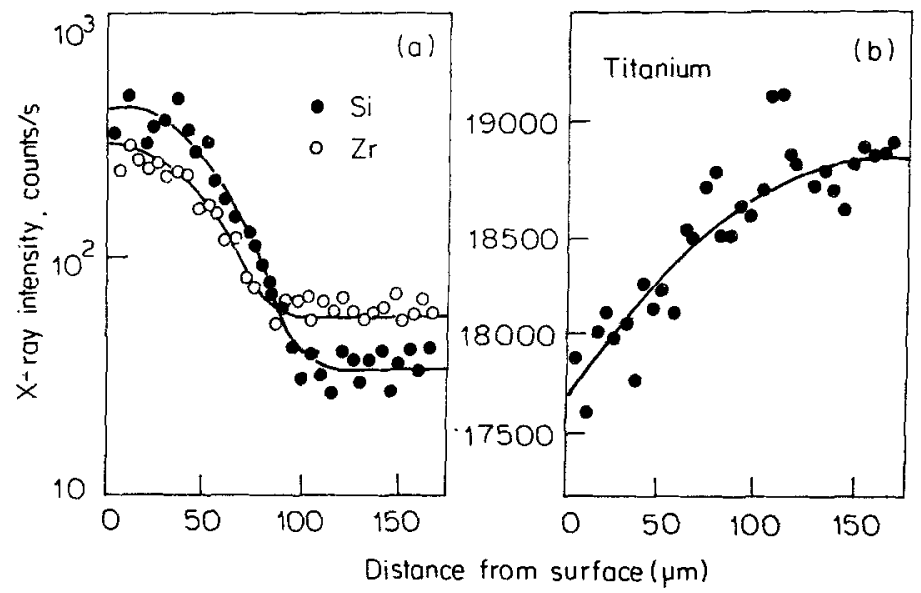

Figure 5. (a) Composition-depth profile as determined by scanning electron probe microanalysis showing diffusion of $\mathrm{Zr}$ and $\mathrm{Si}$ in the as-cast titanium due to interfacial reaction at the metal (titanium)-mould (zircon) interface. (b) Corresponding variation in titanium concentration.

calculation of diffusion depth in casting. The equilibrium structure is $\beta$-Ti $(b c c)$ below the melting point up to $1156 \mathrm{~K}$. The diffusion rate in $\alpha$ - $\operatorname{Ti}(h c p)$ below $1156 \mathrm{~K}$ is very slow and can be ignored in the present calculations. Solute diffusion data in $\beta$-Ti is available only for $\mathrm{O}$ and $\mathrm{Zr}$. For calculation of the diffusion depth, it is necessary to know the diffusion time. This could not be estimated under the present experimental conditions. However, the ratio of diffusion depths for oxygen and zirconium would be equal to the square root of the ratios of their diffusion coefficients:

$$
\left[\frac{x(\mathrm{O})}{x(\mathrm{Zr})_{\text {Theo }}}\right]=\left(\frac{D(\mathrm{O}) t}{D(\mathrm{Zr}) t}\right)^{\frac{1}{2}}=\left(\frac{D(\mathrm{O})}{D(\mathrm{Zr})}\right)^{\frac{1}{2}} \text {. }
$$

The ratio of experimental diffusion depths $[x(\mathrm{O}) / x(\mathrm{Zr})]$ is $7 \cdot 8$. The square root ratios of diffusion coefficients of $\mathrm{O}$ and $\mathrm{Zr}$ calculated from the diffusion data in table 3 , in the temperature region $1500-1940 \mathrm{~K}$ are in the range $8 \cdot 15-7 \cdot 45$. This ratio of theoretical diffusion coefficients $\left[(D(\mathrm{O}))^{\frac{1}{2}} /(D(\mathrm{Zr}))^{\frac{1}{2}}\right]$ is in good agreement with the experimental ratio of diffusion depths. $[x(\mathrm{O}) / x(\mathrm{Zr})]$ over a large temperature range $(1500-1940 \mathrm{~K})$. The good agreement between theoretical and experimental calculations over the temperature range $1500-1940 \mathrm{~K}$ confirms the validity of observed and assumed diffusion depths for zirconium and oxygen in $\beta$-Ti.

3.1d Reactions at the mould interface: The reacted zone in the mould adjacent to the titanium casting interface was found to be $2-5 \mathrm{~mm}$. This corresponds to the distance at which the colour of the mould mix altered from grey to black. The mould area at distance greater than $5 \mathrm{~mm}$ did not appear to have been affected. The reacted sand at the interface was analysed for identification of reaction products by $\mathrm{X}$-ray diffraction (table 2). The phases that were identified in addition to the mould constituents were $\mathrm{TiO}_{2}, \mathrm{TiO}, \mathrm{Ti}_{4} \mathrm{O}_{7}, \mathrm{Ti}_{5} \mathrm{Si}_{3}$ and $\mathrm{Na}_{0.23} \mathrm{TiO}_{2}$. The formation of $\mathrm{Ti}_{5} \mathrm{Si}_{3}$ is indicative of the fact that silicon is released as a consequence of reduction 
Table 3. Products present in the reacted interface mould and in the bulk zircon mould.

\begin{tabular}{|c|c|c|}
\hline \multirow{2}{*}{$\begin{array}{l}\text { Products identified by } \\
\text { X-ray diffraction }\end{array}$} & \multicolumn{2}{|c|}{ Location } \\
\hline & Bulk & Interface \\
\hline $\mathrm{SiO}_{2}$ & $\mathbf{P}^{*}$ & A \\
\hline $\mathrm{Na}_{2} \mathrm{ZrSi}_{4} \mathrm{O}_{11}$ & $\mathbf{P}$ & $\mathbf{P}$ \\
\hline $\mathrm{Na}_{2} \mathrm{ZrO}_{3}$ & $\mathbf{P}$ & $\mathbf{P}$ \\
\hline $\mathrm{Ti}$ & A & A \\
\hline Si & A & $\mathbf{A}$ \\
\hline $\mathrm{Ti}_{5} \mathrm{Si}_{3}$ & $\mathrm{~A}$ & $\mathbf{P}$ \\
\hline $\mathrm{TiO}_{2}, \mathrm{TiO}, \mathrm{Ti}_{4} \mathrm{O}_{7}$ & A & $P$ \\
\hline $\mathrm{Na}_{0 \cdot 23} \mathrm{TiO}_{2}$ & $\mathbf{A}$ & $\mathbf{P}$ \\
\hline
\end{tabular}

The major constituents Zircon, $\mathrm{ZrO}_{2}$ and $\mathrm{Na}_{2} \mathrm{CO}_{3}$ were present in the bulk and the reacted interface.

*A-absent, P-present.

of silica or silicates by liquid titanium. The free silicon combines with titanium to form $\mathrm{Ti}_{5} \mathrm{Si}_{3}$. The formation of $\mathrm{Na}_{0.23} \mathrm{TiO}_{2}$ results from the reaction of liquid titanium with sodium bearing compounds present in the mould. The entrapped titanium reacts with moisture and oxides to form different titanium oxides.

\subsection{Reactivity of titanium during investment casting}

In order to ascertain the approach of evaluation of reactivity, microhardness and concentration profiles were obtained for titanium cast by the investment process. The investment cast products are expected to yield contamination free surfaces with high degrees of dimensional accuracy. It has been suggested above that microhardness profiles are indicative of the diffusion depth of oxygen. To confirm this, concentration profiles for oxygen and metallic species (Y) from the refractory oxide $\left(\mathrm{Y}_{2} \mathrm{O}_{3}\right)$ used as face coat were determined by a more sensitive technique, secondary ion mass spectrometry (SIMS). Diffusion profiles of $\mathrm{O}$ and $\mathrm{Y}$ are presented in figures 6 and 7 respectively. The profile for titanium was also recorded along with $\mathrm{O}$ and $\mathrm{Y}$. In figures 6 and 7 the intensity counts for $\mathrm{Y}$ and $\mathrm{O}$ have been normalised with respect to titanium. As of before, the diffusion depth can be considered as the distance at which the concentration profile for the element becomes invariant. The qualitative behaviour of the oxygen profile is similar to that of the microhardness profile (figure 8). The oxygen profile (figure 6) exhibits a diffusion depth of about $550 \mu \mathrm{m}$ which is in agreement with the microhardness data (figure 8). The SIMS data on oxygen contamination confirms the assumption that microhardness profile is representative of the oxygen profile and the distance from the mould-metal interface at which the invariant behaviour commences is the diffusion depth of oxygen. There is, however, a difference in the depth of diffusion zone in investment cast rods $(550 \mu \mathrm{m})$ and zircon mould cast $(700 \mu \mathrm{m})$. This difference in diffusion depth can be attributed to the faster cooling rate of rods cast in an investment mould (shell thickness $5 \mathrm{~mm}$ ) as compared to a zircon mould (mould wall thickness $50 \mathrm{~mm}$ ). It can be inferred from these results that the depth of diffusion zone is influenced by the rate of heat transfer during solidification of the casting. 


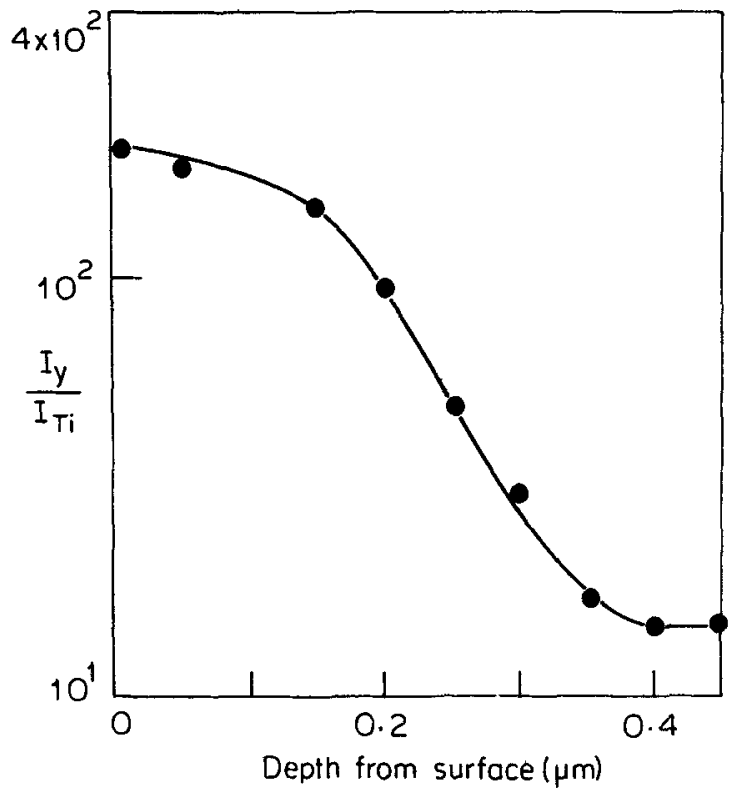

Figure 6. Composition-depth profile for $\mathrm{Y}$ in $\mathrm{Ti}$ cast in an investment mould as determined by secondary ion mass spectrometry (SIMS) of titanium.

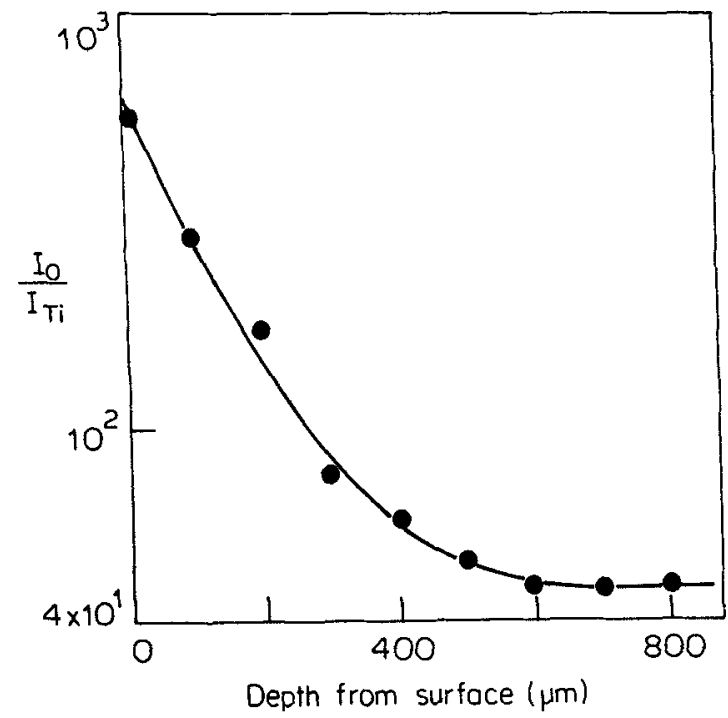

Figure 7. Composition-depth profile for oxygen in titanium as determined by secondary ion mass spectrometry (SIMS).

\section{Conclusions}

(i) Microhardness profiles starting from the metal-mould interface and analysis of oxygen contamination provides a semi-quantitative method for evaluation of reactivity of titanium with mould-mix. 


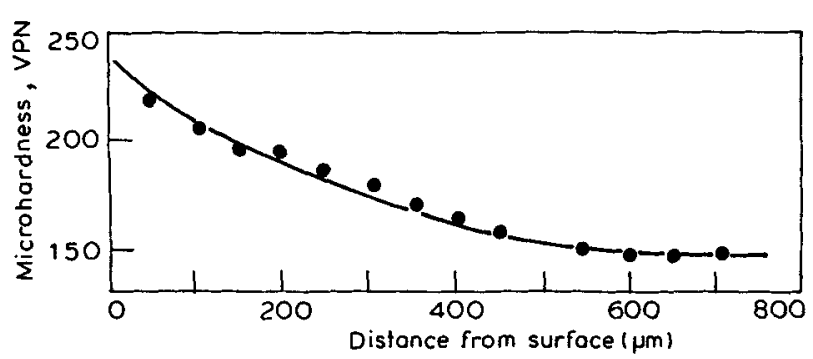

Figure 8. Microhardness as a function of distance from the surface for investment cast titanium.

(ii) Two distinct stages of reaction of titanium with a zircon mould can be delineated on the basis of the microhardness and solute diffusion profiles:

(a) The interior of the casting is characterised by low microhardness, invariant with distance. Contaminants are uniformly distributed because of turbulence of the liquid stream during mould filling.

(b) The second region is characterised by a sharp decrease in microhardness as a function of distance from the surface. After the decay of turbulence in the metal, the metal-mould reaction continues at the interface. The solutes that dissolve into titanium from the mould diffuse away from the interface into the bulk. The diffusion depth for oxygen is larger than for metallic solutes. The distance at which the microhardness becomes invariant represents the diffusion depth of oxygen in titanium casting.

(iii) The variation of microhardness as a function of depth follows a behaviour identical to that of oxygen concentration implying that microhardness profiles can primarily be considered to be indicative of variation in oxygen concentration.

(iv) The reaction of liquid titanium with the zircon mould mix produces compounds such as $\mathrm{TiO}_{2}, \mathrm{TiO}, \mathrm{Ti}_{4} \mathrm{O}_{7}, \mathrm{Na}_{0 \cdot 23} \mathrm{TiO}_{2}, \mathrm{Ti}_{5} \mathrm{Si}_{3}$ at the mould interface.

(v) Oxides from the mould mix are not completely dissolved by liquid titanium. Oxygen from the mould is preferentially transferred to liquid titanium leaving behind metallic constituents in the mould mix as lower oxides or intermetallics of titanium.

\section{Acknowledgements}

RLS, TKN and RDKM wish to thank Dr P Rama Rao for encouragement. The valuable help of Mr V V Rama Rao in EPMA studies is acknowledged.

\section{References}

David D, Gracia E A and Beranger G 1980 Proceedings of Titanium 1980 (eds) H Kimura and O Ozumi (Warrendale: The Met. Soc. AIME) p. 537

Fores F H 1987 J. Met. 393

Ignatov D V, Sokyniansky L F and Shinyaev A Ya 1973 Titanium science and technology (eds) R I Jaffee and H M Burte (New York: Plenum) p. 2535

Mahoney M V and Paton N E 1977 The effect of minor alloying elements on mechanical properties of titanium alloys, AFML Report-TR-75-56, AFML Ohio 
Mukherjee D, Saha R L and Chakravorty C R 1985 Trans. Indian Inst. Met. 38465

Murray J L and Wriedt R A 1986 Binary alloy phase diagrams (ed.) T B Massalski (Ohio: American Society for Metals) p. 1789

Newman J R 1980 Metals handbook (Ohio: American Society for Metals) vol. 3, p. 407

Pavlinov L V 1967 Fiz. Metal. Z. Metalloved. 24272

Raghavan V 1985 Materials science and engineering (New Delhi: Prentice Hall of India) p. 172

Saha R L, Nandy T K, Misra R D K and Jacob K T 1989 Int. Cast. Metals J. (submitted).

Tylecote R F 1979 A history of metallurgy (London: The Metals Soc.) p. 5

Thorne J K and Barice W J 1988 SAMPE Q. 2024 